\title{
O papel ativo da criança em situações lúdicas na Educação I nfantil
}

\section{The active role of the child in playful situations in Early Childhood Education}

\section{El papel activo del niño en situaciones lúdicas en la educación infantil}

\author{
Eloína Ariana Ribeiro Damasceno Silva* \\ Universidade Federal do Vale do São Francisco - UNIVASF, Petrolina, Pernambuco, \\ Brasil
}

\section{Melina de Carvalho Pereira**}

Universidade Federal do Vale do São Francisco - UNIVASF, Petrolina, Pernambuco, Brasil

\begin{abstract}
RESUMO
Este estudo investigou o papel ativo da criança na Educação Infantil em interações lúdicas com pares de idade e situações lúdicas, dirigidas pelo educador. Parte-se de uma compreensão sociointeracionista do desenvolvimento e da brincadeira como contexto relevante para a observação do comportamento infantil (Carvalho, Pedrosa \& RossettiFerreira, 2012). Foram utilizadas videogravações, com crianças de 2 a 4 anos e os respectivos educadores em suas salas de aula, em dois Centros Municipais de Educação Infantil (CMEI) da cidade do Recife. Por meio de uma análise microgenética dos dados, observou-se a capacidade das crianças para se adaptar ativamente a situações e extrapolar o uso convencional de objetos, criando brincadeiras através do material disponibilizado pelo adulto, sendo flexíveis aos fatos ocorridos e até mesmo aos acontecimentos espontâneos. Percebeu-se que os pequenos exercitam seu papel ativo ao subverter a ordem da brincadeira, dos objetos e também a disposição dos equipamentos da sala, trazendo elementos presentes no seu cotidiano de forma criativa. Destaca-se a necessidade de se pensar em metodologias que enfatizem os pontos de vista da criança, considerando-a como construtora ativa de significações.
\end{abstract}

Palavras-chave: crianças, brincadeiras, educação infantil.

\section{ABSTRACT}

The goal of this study is to investigate the active role of children in the context of early childhood education during play interactions with peers in situations controlled by the educator. Starting from socio interactionist understanding of development and child play as a relevant context for the observation of child behavior (Carvalho, Pedrosa \&amp; Rossetti-Ferreira, 2012). Video recordings were used, with children aged 2-4 years along with their respective teachers within their classrooms in two Municipal Centers for 
Early Childhood Education (CMEI) from Recife. Through a micro genetic analysis of data, it was possible to remark the children's ability to actively adapt to situations and extrapolate the conventional use of objects, creating games through the material provided by the adult, being flexible with the events and even to spontaneous outcomes. It was also remarked that the little ones exercise their active role by subverting the order of the playing situation, of the objects and also of the placement of the room equipment, bringing, in a creative manner, elements present in their daily lives. There is a need to think about methodologies that emphasize the points of views of the child, considering it as an active builder of meaning.

Keywords: children, play, childhood education.

\section{RESUMEN}

Este estudio investigó el papel activo del niño en la educación infantil en interacciones lúdicas con pares de edad y situaciones lúdicas dirigidas por el educador. Se parte de una comprensión sociointeracionista del desarrollo y del juego como contexto relevante para la observación del comportamiento infantil (Carvalho, Pedrosa \&amp; Rossetti-Ferreira, 2012). Se utilizaron videograbaciones (unos 324 minutos), con niños de 2 a 4 años y los respectivos educadores en sus clases, en dos Centros Municipales de Educación Infantil (CMEI) de la ciudad de Recife. Por medio de un análisis micro-genético de los datos, se observó la capacidad de los niños para adaptarse activamente a situaciones y extrapolar el uso convencional de objetos, creando juegos a través del material providenciado por el adulto, siendo flexibles a los hechos ocurridos e incluso a los acontecimientos espontáneos. Se percibió que los pequeños ejercitan su papel activo al subvertir el orden del juego, de los objetos y también la disposición de los equipos de la sala, trayendo elementos presentes en su cotidiano de forma creativa. Se destaca la necesidad de pensar en metodologías que enfaticen los puntos de vista del niño, considerándola como constructora activa de significaciones.

Palabras clave: niños, jugar, educación infantil.

\section{0 papel ativo da criança em interações lúdicas na Educação Infantil}

O presente estudo está inserido na área da Psicologia do Desenvolvimento e dialoga com a Educação Infantil. Com intuito de enfatizar as habilidades infantis, e fortalecer as discussões que são contrárias à cultura adultocêntrica, que não percebe as competências das crianças, usando como parâmetro o adulto, compreende-se que a criança é ativa e sujeito biopsicossocial na construção da cultura.

Carvalho, Pedrosa e Rossetti-Ferreira (2012) comentam que, embora na espécie humana a criança nasça com uma imaturidade orgânica acentuada, em comparação com muitos filhotes de outras espécies de animais sociais, o repertório interativo do bebê humano é extremamente sofisticado e supõe a presença do parceiro de espécie para garantir seu desdobramento. Amorim (2012) sinalizam que o alto grau de organização perceptiva e expressiva que o bebê humano possui é o que permite o intercâmbio com o outro. Entende-se que 
desenvolvimento humano ocorre, por meio de uma rede de cuidado, onde cada parceiro de interação modifica e é modificado pelo outro, podendo sempre transformar seus posicionamentos e os significados diversos que atribui ao mundo, ao outro e a si mesmo.

É importante frisar que, principalmente para criança, essa interação vai ocorrer na brincadeira, fenômeno universal e uma das características mais expressivas na infância humana (Meirelles, 2014; Pontes, \& Magalhães, 2003). Bichara, Lordelo, Carvalho, \& Otta (2009) apresentam a brincadeira como um sistema comportamental que ajuda o indivíduo a se adaptar ao mundo. O brincar é necessário não apenas para adquirir habilidades físicas, mas especialmente para criação dos vínculos sociais. Afinal, é na brincadeira que a criança expressa seus modos de agir, pensar, relacionar, interpretar e atribuir sentido ao mundo e às coisas, não se contentando em repetir o que é dado culturalmente, mas sendo ativa em todo seu processo de desenvolvimento.

A brincadeira enquanto prática cultural é permeada por rituais transmitidos, repetidos ou recriados de acordo com o ambiente sociocultural. Essa transmissão se dá no grupo de brinquedo, muitas vezes, sem a interferência de adultos. No grupo de brinquedo as crianças estabelecem redes de relações que beneficiam a atribuição de papéis no desenrolar de interações, onde conhecimentos, regras e procedimentos são trocados, reformulados, criados e repassados (Carvalho \& Pedrosa, 2002; Carvalho, Magalhães, Pontes, \& Bichara, 2003; Corsaro, 2011; Lucena \& Pedrosa, 2014).

A sociologia da infância também dá destaque à participação da criança na cultura, enfatizando a sua capacidade de modificar e ressignificar o que Ihe cerca (Sarmento, 2003; Corsaro, 2011). Para Corsaro (2011), as crianças não recebem passivamente os estímulos, sendo moldadas para atingir o potencial adulto, pelo contrário, estas possuem a competência social de produzir e promover mudanças no contexto em que vive e se relaciona, fato que o autor citado nomeia de "reprodução interpretativa".

Diante disso, diversos pesquisadores e estudiosos da infância (Carvalho, Pedrosa, \& Rossetti-Ferreira, 2012; Gray, 2011, 2013; Lucena \& Pedrosa, 2014; Meirelles, 2014; Viana \& Pedrosa, 2014) pontuam a necessidade de continuar tecendo essas discussões, a fim de difundi-las nos contextos educacionais, proporcionando metodologias mais compatíveis com as reais necessidades das crianças. Sarmento (2003), por exemplo, argumenta que o contexto educacional deve ser pensado a partir da perspectiva infantil, reconhecendo as crianças como atores sociais, ao considerar suas falas, visões e experiências.

A professora Ana Maria Almeida Carvalho em entrevista concedida a Associação Brasileira de Psicologia do Desenvolvimento (Carvalho, 2015) relata que, ao estudar a criança, observando suas brincadeiras 
e interações, é possível alcançar conhecimentos acerca da ontogênese humana e habilidades sociais das crianças. A criança está sempre em mudança, adquirindo novos repertórios, revelando-se de maneira surpreendente. Carvalho (2015) ressalta ainda, a necessidade de estudar a criança em situações cotidianas, apreendendo mais sobre as culturas infantis por meio da observação dos seus comportamentos.

Pereira, Lira e Pedrosa (2011) comentam que as crianças "engajadas no brincar, atividade de alta prioridade motivacional nesse período de desenvolvimento, [...] empenham-se na realização de seus propósitos lúdicos com parceiros, revelando muito do que querem, sabem, ou idealizam" (p. 47). Contudo, mesmo sendo a brincadeira o lugar "ecologicamente relevante" (Pedrosa, 2005) para investigação da criança, permitindo observar processos de significação e de aquisição cultural, infelizmente o lúdico ainda tem sido, costumeiramente, negligenciado na Educação.

Gomes (2007), ao investigar o papel do lúdico especificamente na educação infantil, menciona que devido à concepção errônea acerca do brincar, associando-o como uma atividade supérflua ou "enrolação de aula", algumas escolas não o valorizam, praticando-o apenas como uma recreação. No estudo a pesquisadora discute que, quanto melhor a qualificação profissional do educador, mais este tem a possibilidade de estar aberto às atividades lúdicas, dentre elas a brincadeira livre infantil, reconhecendo a importância do gozo gratuito que a mesma proporciona.

Sendo assim, esse trabalho busca investigar o papel ativo da criança em situações lúdicas na Educação Infantil. Especificadamente, buscou-se descrever e analisar episódios interacionais que evidenciassem o papel ativo da criança em situações lúdicas a) livres entre pares de idade e b) dirigidas pelo adulto (professor). Nas cenas episódicas buscou-se destacar as ações das crianças (movimentos, gestos, expressões, vocalizações, falas, etc.) que, na interação com parceiros sociais, são indícios do seu protagonismo.

\section{Método}

\subsection{Participantes}

Crianças, de ambos os sexos, com idade variando entre 2 e 4 anos, videogravadas em situações de grande grupo, na sala a que pertencem, em dois Centros Municipais de Educação Infantil. No momento da videogravação também estavam presentes os professores responsáveis pelas turmas investigadas. Os registros videogravados foram realizados anteriormente pelo grupo de pesquisa da segunda autora, pertencentes à base de dados do 
laboratório na qual a pesquisadora está vinculada. A vantagem de se usar esse material videogravado está na grande quantidade de imagens existentes, sendo possível explorá-las, extensivamente, para delimitar o papel ativo das crianças em situações de observação. $\mathrm{Na}$ primeira situação de coleta, participaram da pesquisa 20 crianças de dois anos de idade que frequentavam o Grupo I de um Centro Municipal de Educação Infantil (CMEI), da cidade do Recife, que atende a famílias de camada de renda média e baixa. No segundo caso, participaram 19 crianças de 3 a 4 anos de idade do Grupo III de outra instituição CMEI da cidade do Recife, que atende a famílias de camada de renda baixa. Foram seguidas todas as exigências do Comitê de Ética em Pesquisa. Após aprovação do projeto, todos os pais assinaram o Termo de Consentimento Livre e Esclarecido (TCLE), com permissão para participação de seus filhos com divulgação de imagens para fins de formação de docentes e divulgação científica. Os riscos e benefícios da pesquisa foram traçados no momento em que foi submetido ao comitê de ética, mas algumas precauções do pesquisador para dirimir possíveis constrangimentos em situação de coleta de dados estão mencionadas no subitem "procedimentos de coleta" a seguir.

\subsection{Procedimento geral}

A coleta de dados tem uma característica peculiar, uma vez que foram examinadas sessões de observação videogravadas a fim de serem selecionadas as ocorrências (episódios) em que uma ou mais crianças exercem um papel ativo no ambiente (criação de brincadeiras, recaracterização do espaço proposto pelos educadores, falas e gestos que demonstrem protagonismo no ambiente, etc.). As sessões que foram examinadas referem-se às situações de grandes grupos, isto é, um grande número de crianças presentes no momento da videogravação. No primeiro caso, as observações foram realizadas no grande grupo etário, no momento em que brincavam sob a supervisão de educadores, mas em atividades não-dirigidas, ou seja, em situação de brincadeira livre, com material disponibilizado pelo CMEI. Tal procedimento foi realizado tendo em vista a valorização de suas rotinas e a presença das educadoras e auxiliares, no intuito de evitar possíveis estranhamentos e reações negativas das crianças se levadas para um lugar não habitual, o que poderia causar constrangimentos por terem apenas dois anos e, assim, prejudicar o trabalho investigativo. As educadoras, apesar de presentes, não propunham atividades específicas, mas deixavam os objetos do próprio CMEI (brinquedos, colchonetes, etc.) à disposição das crianças para manuseio. Entretanto, intervinham sempre que necessário para confortar alguma criança, eliminar riscos ou dirimir conflitos que surgissem. $O$ foco das filmagens foi dirigido, 
preferencialmente, às crianças, mas, em alguns momentos, registrou-se a interferência da educadora que as atendeu em suas necessidades de conforto e proteção. Esse grupo de crianças investigado foi videogravado duas vezes por semana, durante um período de quarenta e cinco dias, perfazendo um total de 11 sessões de observação com duração média de 24 minutos. No segundo caso, foram videogravadas duas situações lúdicas dirigidas pelo professor denominadas de "rodinha", com duração média de 30 minutos cada. Este era um momento da rotina da creche em que a professora se reunia com a turma (19 crianças) e promovia uma conversa com as crianças ( 3 a 4 anos) sobre alguma temática específica, contava uma história ou outra atividade que considerasse pertinente.

\subsection{Procedimento de análise}

Foi realizada uma análise microgenética dos dados; cada episódio em que se identificava o papel ativo infantil foi analisado a partir da descrição das falas e expressões verbais das crianças, bem como de sua mímica fisionômica e mesmo corporal, posicionamento no espaço, disputa ou concessão de objetos, trocas de brinquedos e quaisquer outras pistas que parecessem relevantes. Adotou-se para este trabalho o conceito de episódio definido por Pedrosa e Carvalho (2005): "uma sequência interativa clara e conspícua, ou trechos de registros em que se pode circunscrever um grupo de crianças a partir do arranjo que formam e/ou atividade que realizam em conjunto" ( $p$. 432).

\section{Resultados e Discussão}

Nas 13 sessões observadas durante os dois momentos de coleta de dados, foram recortados 41 episódios de trechos de registro em que se percebeu o papel ativo da criança. No entanto, neste recorte do trabalho, foram selecionados apenas quatro, utilizando como critério aqueles mais representativos do conjunto de episódios, embora outros trechos também sejam citados no decorrer da argumentação, incrementando a análise empreendida.

Inicialmente, para melhor organização, serão analisados os dados que foram coletados em situação de brincadeira livre com crianças de 2 anos de idade, em seguida comparados com dados provenientes de situações dirigidas pelo professor com crianças de 3 e 4 anos, pois a diferença de idade entre as crianças participantes das duas coletas permite um arsenal de competências diferentes em cada uma das situações. 


\subsection{Episódio 1: Os diferentes usos da Cenoura}

Data 11/12/2008 (Início 02min18seg / Término 18min 00seg) Crianças envolvidas e idade (ano/meses): Tiffani $(2,8)$; Nathalia $(2,10)$; Claudino $(1,10)$; Vinícius $(2,5)$; Williane $(1,11)$; Tarcio $(2,8)$; Arthur $(2,6)$.

A sala foi disposta pelas educadoras com objetos plásticos de comida e também pratos, cestinhas, talheres e copos. A maioria das crianças brinca, juntamente com a professora, de comidinha, sentadas no chão. Tiffani está com uma cenoura de plástico na mão, ela sobe numa cadeira e após alguns segundos começa a cantar, segurando a cenoura como se fosse um microfone. Os colegas que estão perto dela (Nathalia, Claudino e Vinícius) olham para sua direção e observam. Vinícius sorri e vai até ela, subindo na cadeira ao lado. Tiffani mexe o corpo cantando, leva a cenoura na boca e sorri; Williane e Nathalia também sorriem. Tiffani oferece a cenoura a Vinícius; ele morde e prontamente ela puxa a cenoura, retirando dele, com a expressão de desapontamento. Segundos depois, volta a cantar, agora com os pés ritmados e dançando. Tiffani aponta a cenoura para Williane, que estava assistindo sua apresentação, diz algo que não se compreende, parece convidá-la para cantar. Em seguida, volta a cantar e dançar. Simultaneamente, Williane sai do seu lugar e vai até a cadeira que antes Vinícius ocupava, subindo nela. Tiffani coloca o microfone perto da boca de Williane. Elas saem do campo de imagem por alguns segundos, mas Tiffani continua cantando, com um tom de voz ainda mais alto, já Williane se distrai com outra atividade perto dali. Tarcio é o próximo a subir na cadeira ao lado de Tiffani, que incansavelmente continua a performance musical, levantando os braços e sacodindo as mãos. Em algumas pausas rápidas, ela coloca a cenoura na boca e parece querer mordê-la. Tarcio desce da cadeira e corre para pegar algo, depois retoma ao lugar, trazendo nas mãos uma garrafinha, que usa como microfone, cantando timidamente. Tarcio se distrai, usando a garrafa para bater na janela. Tiffani continua a cantar, Julia a assiste e dança. Durante aproximadamente três minutos Tiffani continua cantando com a cenoura "microfone", fazendo gestos com as mãos e dançando, havendo pequenas pausas. Nathalia se aproxima, Tiffani oferece-lhe o microfone, as duas dançam e o microfone é compartilhado por cerca de dois minutos, até que Nathalia se distrai. Tiffani aproxima a cenoura da boca de Tarcio, para que ele também cante. Passando-se aproximadamente três minutos, Tiffani continua em cima da cadeira, ao seu lado está 
Tarcio. Ele segura nas mãos um gato de pelúcia e a garrafinha. Tiffani coloca a cenoura sobre os olhos, cobrindo-os, depois tira e segura a cenoura perto de um olho. Em seguida, tenta ajeitar a maneira como Tarcio está segurando o gato e lhe diz algo não compreensível, a impressão é que ela os arruma para saírem bem na foto, pois a garota coloca novamente a cenoura próxima ao olho como se fosse tirar uma foto. Tarcio pega uma garrafinha que estava segurando e também coloca no seu olho. Os dois continuam juntos, até que Tarcio desce da cadeira e Tiffani o acompanha. Os dois saem do campo de imagem. Tiffani ainda canta utilizando a cenoura, mas em outro lugar. Artur se aproxima dela, também com uma cenoura nas mãos, escuta-se: "pá, pá, pá...", ele mira a cenoura e faz sons de tiros, Tiffani o imita apontando sua cenoura para Artur. Depois, rapidamente, Artur canta usando a cenoura e se retira. Tiffani continua cantando até que se distrai com outra atividade, mas ainda segurando a cenoura, levando algumas vezes na boca e mordendo.

O episódio descrito ilustra como a criança tem a capacidade de se adaptar ativamente a situações e extrapolar o uso convencional de objetos, transformando-os imaginariamente, a fim de que estes possam ter o significado que desejam ou que necessitam para determinada ocasião. Enquanto a maioria das crianças brinca de comidinha com a professora, Tiffani, ao subir na cadeira com uma cenoura nas mãos, encontra aparato suficiente para desenvolver uma performance musical com criatividade e inovação. Nas mãos dessa criança, a cenoura, que também foi utilizada de forma convencional, fazendo de conta que estava mordendo, passa a ser usada como microfone. A cadeira permitiu que Tiffani estivesse numa posição mais alta que as crianças em volta e tornou-se seu palco; os colegas que riem e assistem sua apresentação representaram sua plateia, de modo que até interagem quando solicitados, a exemplo de Williane que aceita o convite da "artista" e toma um lugar no palco, ao subir na cadeira ao lado.

Tiffani não apenas canta, mas realiza movimentos com as mãos, mexe com os pés ritmadamente e sacode as mãos. Há momentos em que sua voz se destaca entre as vozes da sala, o volume da voz é alto e o ritmo constante, ela não se cansa de cantar e dançar, de uma maneira tão contagiante que a colega Julia que está ali por perto, para, admirando-a, assistindo e se envolvendo, a ponto de também dançar. Nathalia, que desde o início estava observando, não resiste e é a próxima a se juntar com a colega. Tiffani parece interpretar sua ação com um pedido, oferece-a o microfone e as duas dançam juntas. Ela demonstra gostar de compartilhar o microfone, parece sentir que está chamando a atenção dos colegas. É visível como no 
decorrer do episódio a cadeira ao lado de Tiffani recebe convidados que se interessam pela performance da pequena cantora e dançarina. Outro fator bastante relevante é que, embora Tiffani passe a maior parte do tempo centrada em utilizar a cenoura como um microfone, mostrando desapontamento quando o Vinícius não entende seu convite para cantar e acaba mordendo a cenoura, ela reconhece o uso convencional desse objeto. Como também se mostra disposta a utilizá-la de outra forma quando isso a possibilita a interação com outros parceiros sociais, como é o caso de Artur. Ao se encontrarem, ambos compartilham os sentidos/significados dados ao objeto, como se um dissesse: "minha cenoura pode ser microfone" e o outro "a minha pode ser uma arma", mas ainda assim, experimentando cada um da inventividade do outro. Em outro momento, ao interagir com Tarcio, ela ousa usar a cenoura como uma câmera fotográfica/binóculo. Os diferentes usos da cenoura foram listados na Tabela 1 a seguir:

Tabela 1

Diferentes usos da cenoura

\begin{tabular}{ll}
\hline Microfone & $\begin{array}{l}\text { Tiffani começa a cantar, segurando a cenoura com as mãos como se fosse um } \\
\text { microfone. }\end{array}$ \\
\hline Comida & $\begin{array}{l}\text { Tiffani oferece a cenoura a Vinicius; ele morde e em seguida ela puxa a } \\
\text { cenoura (descontentamento com o uso canônico que o parceiro fez do objeto). }\end{array}$ \\
\hline Arma & Artur segura a cenoura como uma arma e grita: "Pá, pá, pá...". \\
\hline & $\begin{array}{l}\text { Tiffani coloca a cenoura sobre os olhos, cobrindo-os, depois tira e segura a } \\
\text { cenoura perto de um olho. Em seguida, a garota coloca novamente a cenoura } \\
\text { próxima ao olho como se fosse tirar uma foto. Tarcio pega uma garrafinha } \\
\text { que estava segurando e tambem coloca no seu olho. }\end{array}$ \\
\hline $\begin{array}{l}\text { Nota: durante uma sessão de brincadeira, as crianças reunidas dão diversos significados (criações de faz } \\
\text { de conta) ao mesmo objeto: a cenoura. }\end{array}$
\end{tabular}

Esse jogo simbólico de transformar objetos em coisas diferentes, o que caracteriza o faz de conta, é possível quando a criança já compreende 0 uso intencional que os adultos fazem de objetos/artefatos e desprendendo-se disso, passa a utilizá-los "inapropriadamente" de modo lúdico. Corsaro (2011), menciona que:

De acordo com essa visão reprodutiva, as crianças não se limitam a imitar ou internalizar o mundo em torno delas. Elas se esforçam para interpretar ou dar sentido a sua cultura e a participarem dela. Na tentativa de atribuir sentido ao mundo adulto, as crianças passam a produzir coletivamente seus próprios mundos e cultura de pares (p. 36).

Uma semana depois do episódio descrito, as crianças estavam na mesma sala, com outros objetos disponíveis como bolinhas, rolos de 
plástico filme e de fita adesiva, garrafinhas com pedrinhas, elástico, colchonetes e almofadas. Tiffani volta a cantar e dançar, mas agora fazendo uso do rolo de plástico filme como microfone e o rolo de fita adesiva como pulseira. Ela circula pela sala observando a brincadeira dos colegas, mas sempre retornando a sua brincadeira individual de cantar e dançar.

Nesse dia, mesmo não tendo mais disponível a cenoura, ela utiliza outro objeto para substituí-la. Sua performance continua persistente e ainda mais elaborada, como se imitasse a globeleza ou uma rainha de bateria do carnaval, ela dança fazendo movimentos circulares ao ritmo do samba. Em alguns momentos, o som feito pelas outras crianças, que chacoalham as garrafinhas com pedrinhas em ritmo constante, é a trilha sonora que torna a desenvoltura da menina ainda mais animada. Ao se aproximar da colega Williane que está com um elástico nas mãos, ela pede várias vezes: "Me arruma aqui, Lia!". A menina atende ao pedido de Tiffani, mas logo a dançarina deixa o acessório e continua a dança no ritmo, mexendo os lábios e com a mão segurando o rolo de papelão (microfone). Há ocasiões em que ela faz o movimento de lançar o corpo para frente e depois para trás, jogando a cabeça semelhante a uma cantora famosa da época (J oelma - vocalista da Banda Calypso); mesmo Tiffani tendo o cabelo curto, imita o gesto de jogar os longos cabelos como faz a artista em suas apresentações.

Essa outra sequência de movimentos realizada por Tiffani exemplifica como a criança vai se apropriando da cultura, ao trazer para a brincadeira elementos presentes no seu cotidiano de forma criativa. Seu desempenho ao protagonizar a experiência de cantar e dançar associa-se à descontração e ao gingado nos passos, como também na necessidade de ter acessórios como uma pulseira, o microfone e a ajuda da colega para arrumá-la, como quem se prepara para uma apresentação e se atenta para os detalhes. Sobre isso, Corsaro (2011) comenta que as crianças, apropriando-se de informações do mundo adulto, constroem suas próprias culturas na sua rotina com pares de idade (cultura de pares) que as permitem lidar com suas próprias necessidades.

Outro fator importante nesses episódios, que não podemos deixar de considerar, é a intenção pedagógica das educadoras, que ao planejarem essa atividade, provavelmente pensaram em situações específicas que poderiam ocorrer, a exemplo da brincadeira de comidinha, pois elas se posicionaram no chão juntamente com a maioria das crianças, demonstrando ser essa a brincadeira que era esperada para aquele momento e que prevalecia devido à aceitação de grande parte da turma. Mas Tiffani, fazendo um uso bastante diverso do previamente proposto, inova o uso da cenoura e persiste na sua brincadeira. Isso só foi possível, mediante a liberdade que as 
educadoras deram às crianças, permitindo a exploração dos objetos e não vetando outras brincadeiras, como a construída por Tiffani.

Esses dois episódios são apenas exemplos do que diversas vezes foi encontrado: as crianças subverteram a ordem da brincadeira, dos objetos e até mesmo a disposição dos equipamentos da sala, surpreendendo com seu protagonismo. Dentre os episódios selecionados, há também situações em que: as crianças utilizam revistas e baldes revistas e baldes disponíveis tornam-se, nas mãos das crianças, objetos para brincar de fazer lixo, catando em seguida e colocando dentro dos baldes; as banheiras de boneca dispostas para a brincadeira de casinha tornam-se sandálias para Lua ir para praia; uma carteira posta emborcada no local em que uma criança fez xixi, evitando escorregões até a limpeza chegar, torna-se para Tarcio um cavalo, que ele monta e grita: "O cavalinho vai sair!", atraindo outros colegas para brincadeira, como Tiffani que se aproxima montando na garupa do cavalo imaginário. E ainda, em outra ocasião, as carteiras postas encostadas na parede pelas educadoras, em semicírculo, com intuito de oferecer maior espaço no meio da sala para as crianças brincarem, tornou-se para elas um túnel por onde queriam passar e se divertir.

Percebe-se, portanto, a facilidade que a criança tem de se apropriar de situações, modificando a proposta inicial fomentada pelas educadoras, como também de serem flexíveis aos fatos ocorridos no decorrer da brincadeira inventada e até mesmo nos acontecimentos espontâneos, adicionando ou retirando elementos, como em uma situação de queda não proposital se transforma em uma brincadeira de cair intencionalmente. Corsaro (2011) explica que, nesse processo de socialização contínua, a criança, através da brincadeira, vai expressar aquilo que compreende acerca da cultura em que está inserida, mas também vai encontrar meios de experimentar o mundo, reinventando a realidade.

No episódio a seguir, é possível visualizar como a educadora se portou em um desses momentos de criação infantil, incentivando o faz de conta e participando com as crianças. Tal fato se mostrou bastante relevante, tendo em vista que essa liberdade dada a elas procede da abertura e sensibilidade que esse profissional possui, de estar atento a uma motivação que é intrínseca ao ser humano (o brincar) e fundamental para o desenvolvimento integral nessa faixa etária.

\subsection{Episódio 2: Tiros, fantasma e cachorro}

Data 19/11/2008 (Início 16min46seg / Término 24min06seg)

Crianças envolvidas e idade (ano/meses): Artur $(2,6)$; Tarcio $(2,7)$; Williane $(1,11)$; Samuel $(2,1)$; Lua $(2,4)$; Julia $(2,1)$. 
Artur corre atrás de Tarcio com o rolo nas mãos como se fosse uma arma, ele vai gritando: "Pá, pá, pá!". Tarcio, por sua vez, corre buscando refúgio nos braços da professora. A brincadeira se repete no minuto seguinte, mas logo depois as crianças se distraem. Passando-se quatro minutos, Artur e Tarcio voltam correr um atrás do outro dando tiros. Nesse momento, a professora Marcela levanta do chão e Tarcio agarra-se na sua perna por alguns segundos, depois caminhando próximo à professora. Sem perdê-la de vista, ele volta a dar tiros em direção ao colega. Artur corre para perto dos dois e também se abriga junto à professora. Tarcio pronuncia: "É o medo do fantasma", ela pergunta inclinando para abraçá-los: "É o medo, ui! De que? De que? De que?". Artur responde: "Do au-au", ela repete: "Do au-au?". Artur fica de joelhos, apoiando as mãos no chão, imitando um cachorro e Tarcio faz que está atirando. Eles saem do campo de imagem durante alguns segundos. Ao retornar, Artur se aproxima da professora e dos colegas (Williane, Nathalia e Samuel) que estão ao redor dela imitando um cachorro, a professora Marcela finge está com medo, tremendo as mãos dizendo: "Vai embora cachorro!". Tarcio imita o colega e os dois juntos se aproximam do grupo. As crianças ficam ainda mais próximas da professora, o que demonstra a entrada na brincadeira. Ela comenta: "Olha o cachorro, xô cachorro! Xô Cachorro!". Artur continua brincando de cachorro e gritando alto: "Au, au, au, au!". Tarcio se acolhe com as outras crianças nos braços da professora. Ela incentiva: "Vem cachorrinho! Vem cachorrinho" e tremendo as mãos e levando-as ao rosto, diz: "Ui, ui, ui!". Simultaneamente, Lua que estava próximo dali observando, vem para mais perto e também começa imitar um cachorro, ao lado de Artur. Julia, que brincava sozinha do outro lado da sala, ao ver o movimento, levanta-se e fica em pé, próxima ao grupo, quando Lua e Artur se aproximam, ela corre.

Verifica-se no registro acima como a brincadeira foi se transformando de tiroteio para fantasma e, depois, cachorro. Os novos sentidos dados à brincadeira pelos garotos apontam para sua criatividade, mas também para coerência de que independente da situação, seja num tiroteio, na aparição de um fantasma ou cachorro, se houver medo, o melhor é correr e buscar abrigo. A professora, além de representar um lugar seguro para as crianças, foi incentivadora do faz de conta e mediadora para que outras crianças se envolvessem. Ao chamar "Vem cachorrinho! Vem cachorrinho!", ela parece perceber que as crianças não estavam de fato com medo, mas brincando; e por isso, incentiva a figura amedrontadora, sugerindo que os cachorros venham, dando continuidade ao roteiro de brincadeira proposto. 
No decorrer do faz de conta, observa-se que as crianças vão se agrupando mais perto da professora, que as abraça toda vez que os colegas se aproximam. Lua, que estava envolvida em outra atividade perto dali, logo se interessa em fazer parte da brincadeira e utiliza da imitação como uma estratégia de ser aceita pelo grupo. Julia, de modo semelhante a Lua, percebe o movimento através dos sons emitidos pelos colegas e educadora, mas prefere observar, participando da brincadeira apenas quando os "cachorros" se aproximam latindo, momento este em que ela corre. Esse episódio se estende até o final da gravação da sessão.

Cabe mencionar que, no conjunto das sessões observadas, a educadora interviu em algumas situações para que eles não se machucassem ou mediou a disputa de objetos, mas na maior parte das vezes seu posicionamento era de estimular o faz de conta e garantir a autonomia das crianças, valorizando e participando com elas das construções realizadas. Mesmo quando a iniciativa partia da professora e a criança compartilhava interagindo junto aos colegas, notou-se que a criança continuava sendo inventiva, surpreendendo com ricas elaborações que incrementavam o desenrolar da atividade. Os próximos episódios ilustram bem esses momentos e se refere ao segundo momento de coleta de dados: atividades lúdicas dirigidas pelo professor com crianças de 3 a 4 anos.

\subsection{Episódio 3: A vela}

Data 26/08/2006 (Início: 10min40seg / Término: 12min57seg) Crianças envolvidas e idade (anos): Camile (4); Daniel (4); Beatriz (4) e Laisa (4).

A professora pede para que todos fiquem em pé para esticar o corpo, formando uma roda. Depois começa a dar as instruções: "Todo mundo agora respirar bem fundo!" e, baixando o tom de sua voz, continua: "Faz de conta que a gente está com uma vela na mão, cuidado para não se queimar, essa vela é mágica. Sabia que ela é mágica? Vê só! A gente apaga ela e ela acende." Simultaneamente à fala da professora, Camile, atenta ao que ouve, dobra o braço e segura a vela imaginária; depois com o dedo da outra mão trisca na vela, com a expressão de dor, ela sacode imediatamente a mão, como se tivesse queimado. A professora explica: "Então vamos fazer assim, a gente vai cheirar uma flor, encher o pulmão de ar e depois vamos apagar a vela, tá certo? Com muita força, porque essa vela é teimosa, fica acendendo o tempo todo. Então, uma flor na mão, na outra a vela... Cheira a flor, assopra a vela!". As crianças entram no faz de conta e participam ativamente da atividade, seguindo os passos dados pela professora. Camile diz 
sorrindo: "Apagou de novo!", a professora diz: "Apagou de novo? Ita apagou! Ahh! Meu Deus! Acendeu de novo a vela, olha praí! Vamos ter que apagar, cheira a flor e assopra a vela!". Enquanto isso, Daniel sacode o braço como se a vela estivesse derretendo e algumas crianças sorriem. Camile diz: "Acendeu de novo!", ela fala sorrindo, depois pulando, sacode as mãos. Beatriz e Laisa também sacodem as mãos e sorriem. A brincadeira dura cerca de dois minutos.

Como se percebe, o momento descrito ocorreu durante uma atividade lúdica mediada pela professora, com cunho pedagógico. Chama atenção o modo como a educadora conduziu a atividade, utilizando recursos como a imaginação para aguçar a participação das crianças. O que se tratava apenas de exercícios respiratórios, tornou-se um espetáculo que proporcionou às crianças autonomia para irem muito além do que foi proposto.

Elas, cada uma ao seu modo, seguram a vela e seguem os passos dados pela professora, que fez um alerta: "Cuidado para não se queimar!". Camile, surpreendentemente, não se contentando em tomar cuidado, quis "arriscar", vendo o que poderia acontecer. E, para isso, decide tocar na vela imaginária. Se o episódio terminasse aí, já seria possível analisar a capacidade da criança de trazer a existência sua fantasia, como se a vela se personificasse. Porém, o que acontece logo em seguida, quando Camile toca a vela que não existe e faz expressão de dor, sacudindo a mão como se realmente tivesse se queimado, evidencia a habilidade infantil de criar e externar através dos movimentos suas ideias e emoções que perpassam na sua fantasia.

Viana e Pedrosa (2014) também analisaram episódios interativos e discutiram a importância dos movimentos das crianças para comunicar seu pensamento. Na situação descrita acima, observa-se que mesmo quando a criança já possui linguagem verbal, o movimento continua sendo usado, muitas vezes substituindo-a e dando mais ênfase à brincadeira simbólica. Isso porque a criança traz a existência a vela e consegue dramatizar os efeitos dela na realidade compartilhada. O Referencial Curricular Nacional da Educação Infantil discute esse aspecto. "O movimento para criança pequena significa muito mais que mexer o corpo ou deslocar-se no espaço. A criança se expressa e se comunica por meio dos gestos e das mímicas faciais e interage utilizando fortemente o apoio do corpo" (Brasil, 1998, p. 18).

No decorrer do episódio, nota-se também que Camile se mostrou tão motivada no faz de conta e, ao mesmo tempo envolvida na atividade, que faz questão de mencionar as vezes que sua vela acende. Pode-se dizer que, nesse momento, a atividade deixa de ser criação apenas da professora e as crianças passam a ser coautoras e protagonistas. 
Outro exemplo disso é quando, segurando a vela que acende e apaga, uma das crianças cria o gesto de sacudir o braço, que logo é coletivamente aceito e reproduzido pelas outras através dos risos. As crianças demonstram evitar se queimarem com os respingos da vela imaginária derretida e, juntas, se divertem. Tal fato ratifica a competência social infantil de criar e compartilhar significados por meio de uma atividade lúdica.

Pode-se dizer que, brincando, a criança se apropria de informações socialmente disponíveis, atribuindo significado a si própria e às coisas do mundo a partir da interação com os outros. Nas diferentes ações de seus enredos lúdicos, ela constrói, compartilha e negocia sentidos sobre fenômenos diversos de seu contexto sociocultural (Corsaro, 2011, Carvalho, Pedrosa \& Rossetti-Ferreira, 2012). Isso pode ser visto no episódio abaixo:

\subsection{Episódio 4: “Macaco tem piolho"}

Dia 27/10/2006 (Início: 24min30seg/ Término: 24min45seg) Crianças envolvidas e idade (anos): Marcelo ( 4 anos)

Em uma rodinha com todas as crianças da turma, a educadora realiza um concurso para ver quem imita melhor um macaco e cada criança na sua vez faz os movimentos. A professora ressalta as características dos pulos das crianças e vai sugerindo elementos que podem ser acrescentados. Ela pergunta: "E macaco se coça? Ele se coça assim, ó... Se coça?" e fazendo movimentos de coçar as costas e a cabeça, as crianças se divertem sorrindo, e tentam imitá-la. Marcelo se aproxima do centro e diz: "Ele tem piolho!", ela indaga: "Será que ele tem piolho?".

No episódio acima, a professora propõe um concurso, provavelmente no intuito de exercitar a criatividade das crianças, para que as mesmas tragam aspectos novos para a imitação de um animal, no caso o macaco. Sob a mediação da educadora, as crianças agregam novos elementos em sua performance. Ela acrescenta a coceira, o que faz Marcelo lembrar-se de piolho, pois o fato de se coçar é compreendido pelo garoto como "quem se coça é porque está com piolho".

A situação mencionada demonstra que na brincadeira a criança interpreta as cenas inspirada pelo já foi visto em seu cotidiano. Brincando, ela tem liberdade de expor seus pensamentos e reproduz, interpretativamente, as pistas do adulto, agregando a estas, embelezamentos. No episódio 4, o desenrolar da interação é proposta a partir das intervenções da educadora. No entanto, percebe-se a 
aceitação e a integração dos embelezamentos propostos pelas crianças.

Considerando a motivação intrínseca infantil para o brincar, situações lúdicas parecem propícias à busca de evidências empíricas da apropriação social. As crianças podem trazer valores e conceitos da macrocultura e questioná-los, reconstruí-los ou fortalecê-los, na interação com parceiros de idade semelhante ou adultos.

\section{Considerações Finais}

Os achados descritos neste estudo evidenciam o papel ativo da criança, que independe do contexto de brincadeira livre ou dirigida pelo professor. Ao analisar o enredamento das ações das crianças, notou-se o surgimento de brincadeiras por meio dos objetos disponibilizados pelo adulto, geralmente, subvertendo o que era esperado pelos educadores. Elementos novos também são acrescentados no decorrer de acontecimentos espontâneos, o que demonstra a capacidade criativa que a criança possui ao vivenciar o mundo que a cerca. Tal fato ressalta a importância de revisitar as concepções antigas a respeito da infância, na direção de uma compreensão que destaque suas potencialidades e reais habilidades, pois, não raramente, a criança ainda é pouco percebida em suas capacidades.

Embora este estudo limite-se a descrições episódicas, as situações apresentadas possibilitam ampliar o diálogo da Psicologia do Desenvolvimento com a Educação Infantil. Por meio das evidências empíricas descritas, profissionais de educação e de outras áreas que lidam com criança podem ajustar suas ações e planejamentos, considerando a criança como produtora de saberes e conhecimentos. Destaca-se ainda a necessidade de se pensar em metodologias que tenham como ênfase as experiências infantis e seus pontos de vista.

\section{Referências}

Amorim, K. S. (2012). Processos de significação no primeiro ano de vida. Psicologia: Teoria e Pesquisa, 28(1), 45-53. doi: 10.1590/S0102-37722012000100006

Bichara, I. D., Lordelo, E. R., Carvalho, A. M. A., \& Otta, E. (2009). Brincar ou brincar: eis a questão, perspectiva da psicologia evolucionista sobre a brincadeira. In M. E. Yamamoto \& E. Otta (Orgs.), Psicologia evolucionista (pp. 104-113). Rio de Janeiro: Guanabara-Koogan.

BRASIL (1998). Ministério da Educação e do Desporto. Secretaria de Educação Fundamental. Referencial curricular nacional para a 
educação infantil / Ministério da Educação e do Desporto, Secretaria de Educação Fundamental. - Brasília: MEC/SEF. Recuperado em 15 de outubro de 2015, Retirado de http://portal. mec.gov.br/seb/arquivos/pdf/volume3. pdf

Carvalho, A. M. A., \& Pedrosa, M. I. (2002). Cultura no grupo de brinquedo. Estudos de Psicologia (Natal), 7(1), 181-188.

Carvalho, A. M. A., Magalhães, C. M. C., Pontes, F. A. R. \& Bichara, I. D. (Orgs.). (2003). Brincadeira e cultura: viajando pelo Brasil que brinca (Vol. 1). São Paulo: Casa do Psicólogo.

Carvalho, A. M. A., Pedrosa, M. I. \& Rossetti-Ferreira, M. C. (2012). Aprendendo com a criança de zero a seis anos. 1a. ed. São Paulo: Cortez Editora.

Carvalho, A. M. A., \& Pontes, F. A. R. (2003). Brincadeira é cultura. In A. M. A. Carvalho, C. M. C. Magalhães, F. A. R. Pontes, \& I. D. Bichara (Orgs.), Brincadeira e Cultura: viajando pelo Brasil que brinca (pp. 15-29). São Paulo: Casa do Psicólogo.

Carvalho, A. M. A. (2015). Algumas reflexões sobre a criança e o processo de desenvolvimento. $X$ Congresso Brasileiro de Psicologia do Desenvolvimento, Belém. Retirado de http://www.cbpd2017.com.br/

Corsaro, W. A. (2011). Reprodução interpretativa e cultura de pares. In F. Muller, \& W. A. Corsaro. Sociologia da Infância (L. G. R. Reis, Trad., 2. ed.). Porto Alegre: Artmed. Originalmente publicado em 1997.

Gomes, M. R. V. C. S. (2007). Entre o livre e o didático: o papel do lúdico na escola de Educação Infantil. In M. F. Costa, V. F. R. Colaço, \& N. B. Costa (Org.), Modos de brincar, lembrar e dizer: discursividade e subjetivação (pp. 140-156). Fortaleza: Edições EFC.

Gray, P. (2011). The Decline of Play and the Rise of Psychopathology in Childhood or Adolescence. American Journal of Play, 3, 443463.

Gray, P. (2013). Free to learn: why unleashing the instinct to play will make our children happier, more self-reliant, and better students for life. New York: Basic Books.

Lucena, J. M. F., \& Pedrosa, M. I. (2014). Estabilidade e transformação na construção de rotinas compartilhadas no grupo de brinquedo. Psicologia: Reflexão e Crítica, 27(3), 556563. doi: 10.1590/1678-7153.201427317.

Meirelles, R. (2014). Cozinhando no Quintal (Vol. 1). São Paulo: Terceiro Nome.

Pedrosa, M. I. (2005). A brincadeira como um lugar "ecologicamente relevante" para a investigação da criança. In Anais do Simpósio Nacional de Psicologia Social e do Desenvolvimento (pp. 3742). Vitória: Programa de Pós-Graduação em Psicologia, Universidade Federal do Espírito Santo. 
Pedrosa, M. I., \& Carvalho, A. M. A. (2005). Análise qualitativa de episódios de interação: uma reflexão sobre procedimentos e formas de uso. Psicologia: Reflexão e Crítica, 18(3), 431-442.

Pereira, M. C., Lira, P. P. B., \& Pedrosa, M. I. (2011). Observando brincadeiras e conversando com crianças sobre família. In L. V. C. Moreira, \& E. P. Rabinovich (Org.), Família e parentalidade: olhares da Psicologia e da História (pp. 41-62). Curitiba: Juruá.

Pontes, F. A. R., \& Magalhães, C. M. C. (2003). A transmissão da cultura da brincadeira: algumas possibilidades de investigação. Psicologia Reflexão e Crítica, Porto Alegre, 16(1), 117-124.

Sarmento, M. J. (2003). Imaginário e culturas da infância. Cadernos de Educação, 12(21), 51-69.

Viana, K. M. P., \& Pedrosa, M. I. (2014). Brincadeiras coordenadas cooperativas e o compartilhamento de intenções em crianças. Psicologia Reflexão e Crítica, 27(3), 564-572. doi: 10.1590/1678-7153.201427318

\section{Endereço para correspondência \\ Eloína Ariana Ribeiro Damasceno Silva \\ Universidade Federal do Vale do São Francisco - UNIVASF \\ Av. José de Sá Maniçoba, S/N, Centro, CEP 56304-917, Petrolina - PE, Brasil \\ Endereço eletrônico: eloina_ariana@msn.com \\ Melina de Carvalho Pereíra \\ Universidade Federal do Vale do São Francisco - UNIVASF \\ Av. José de Sá Maniçoba, S/N, Centro, CEP 56304-917, Petrolina - PE, Brasil \\ Endereço eletrônico: melinamcp@gmail.com}

Recebido em: 11/03/2016

Reformulado em: 08/08/2017

Aceito em: $11 / 08 / 2017$

\section{Notas}

* Graduada em Psicologia pela Universidade Federal do Vale do São Francisco UNIVASF.

** Mestre em Psicologia pela Universidade Federal do Pernambuco - UFPE. Psicóloga do Centro de Estudos e Práticas em Psicologia (CEPPSI) da Universidade Federal do Vale do São Francisco - UNIVASF.

Este artigo de revista Estudos e Pesquisas em Psicologia é licenciado sob uma Licença Creative Commons Atribuição-Não Comercial 3.0 Não Adaptada. 